\title{
Anodic Reactions and the Corrosion of Copper in Deep Eutectic Solvents
}

\author{
T.A, Green*, P. Valverde and S. Roy** \\ Department of Chemical and Process Engineering, University of Strathclyde, Glasgow, Scotland \\ G1 1XJ, United Kingdom.
}

** Electrochemical Society Member

\section{Corresponding author:}

*Todd Green

Department of Chemical and Processing Engineering, University of Strathclyde, Glasgow, G1

1XJ, United Kingdom

Tel: +44 1415745488

e-mail: todd.green@strath.ac.uk

ORCID: 0000-0002-3538-5217 


\begin{abstract}
An analysis of the anodic reaction occurring at soluble copper anodes during the electrodeposition of copper from an ethaline-based deep eutectic solvent (DES) has been performed. It was shown by UV-Vis spectroscopy and electrochemical measurements that the dominant anodic species produced is the $\mathrm{CuCl}_{2}{ }^{-}$complex. In pure ethaline the current efficiency of the anodic process is $100 \%$ and the dissolution valency is one. However, in the presence of $\mathrm{Cu}(\mathrm{II})$ species the apparent dissolution valency measured gravimetrically was typically less than unity, corresponding to an observed mass loss greater than that expected from Faraday's law. Moreover, the apparent dissolution valency showed a marked dependence on the electrode rotation rate, $\mathrm{Cu}(\mathrm{II})$ concentration and the water content of the deep eutectic solvent. These observations were consistent with a corrosion reaction occurring in parallel with anodic dissolution. The most likely corrosion process is the comproportionation reaction: $\mathrm{CuCl}_{4}{ }^{2-}+\mathrm{Cu}$ $\rightarrow 2 \mathrm{CuCl}_{2}{ }^{-}$. Voltammetric data indicate that the rate of this process is controlled by the mass transport of the $\mathrm{CuCl}_{4}{ }^{2-}$ complex to the surface and can readily explain the observed dissolution valency dependencies. Finally, it is noted that complex dissolution of $\mathrm{Cu}$ anodes in deep eutectic solvents makes their implementation as soluble anodes problematic.
\end{abstract}




\section{Introduction}

The use of eutectic-based ionic liquids (ILs) for the electrodeposition of metals and alloys has received considerable attention since its initial introduction by Abbott and co-workers ${ }^{1}$ in 2003. These materials share some of the characteristics of conventional room temperature ionic liquids (RTILs) but possess a number of potential advantages. ${ }^{2,3}$ For example, they can be formulated from relatively low-cost precursors, exhibit low volatility and toxicity, and show a good tolerance to water contamination. They are therefore more likely to be deployed in practical plating systems where such considerations are particularly important. These materials are usually described as deep eutectic solvents (DES) $)^{4,5}$ and a common formulation compromises a mixture of two components: a hydrogen bond donor (HBD) and a hydrogen bond acceptor (HBA). When mixed the HBA and HBD self-associate to form a new eutectic phase with a melting point much lower than the original components. Typically the eutectic temperature is below $100{ }^{\circ} \mathrm{C}$ which makes DES suitable for many plating and surface finishing applications. ${ }^{5-7}$

A widely used DES is 'ethaline' which is formulated from ethylene glycol (HBD) and choline chloride (HBA) in a 2:1 molar ratio. ${ }^{5,6}$ Ethaline has the highest conductivity and the lowest viscosity of all the various DES systems studied. ${ }^{6}$ Additionally, metal chloride salts and metal oxides have a high solubility in ethaline and can therefore be used to formulate practical plating solutions. These 'type-III' DES systems have been used to deposit a wide range of metals including $\mathrm{Al}, \mathrm{Zn}, \mathrm{Fe}, \mathrm{Ni}, \mathrm{Sn}, \mathrm{Cr}, \mathrm{Al}$ and $\mathrm{Cu}^{2-7}$. Studies ${ }^{8-14}$ of copper deposition have been particularly common as it is used extensively in the electronics and microelectronic industries and can be regarded as a model system. Additionally there is a large body of existing studies of 
$\mathrm{Cu}$ deposition from conventional ILs and aqueous systems which can be used to benchmark DES-based processes.

Despite their advantages, a number of limitations of using deep eutectic solvents for metal electrodeposition have been identified. Firstly, the DES solutions are highly viscous and the diffusivity of the electroactive species is correspondingly low. This imposes severe mass transport constraints and deposition rates are low compared to aqueous systems. Operating at high temperatures ${ }^{8,9}\left(>50{ }^{\circ} \mathrm{C}\right.$ ) and the use of ultrasonic agitation ${ }^{9,10}$ have both been applied to improve mass transport rates, but only modest gains are possible with such approaches, and the energy consumption will also be higher. The conductivity of RTIL and DES systems are also low compared to conventional high-temperature ILs and aqueous systems. ${ }^{5,15}$ This increases the energy consumption and also means that the plating process will have poor throwing power. ${ }^{15}$

The use of water additions has also been proposed $^{16}$ to alleviate these problems and the hygroscopic nature of the DES makes water uptake unavoidable unless special precautions are taken. For copper deposition from an ethaline-based DES it was found that $15 \mathrm{wt} \%$ water content resulted in a 2 - 3x improvement in conductivity and diffusivity with minimal influence on the deposit characteristics. ${ }^{16}$ However, the use of water additions is not appropriate in all cases, especially for the deposition of reactive metals or for electronegative metals (e.g. Zn) where the co-reduction of water to form $\mathrm{H}_{2}$ will reduce the current efficiency.

Another technical issue relating to the practical implementation of metal electrodeposition processes using RTILs is the nature of the anode reaction. ${ }^{2,3,6}$ One possibility is to use an 
insoluble anode (e.g. platinum, carbon or DSA) but there are a number of potential disadvantages with this approach. Firstly, the use of insoluble anodes will require the regular addition of metal salts to maintain a constant concentration of the depositing species. Secondly, the electrochemical reactions at an insoluble anode will most likely involve the breakdown of the DES itself leading to the formation of complex byproducts. ${ }^{2,3,6}$ For example, in a study by Haernes and coworkers ${ }^{17}$ employing DSA anodes in an ethaline-based DES it was found that a wide range of organic anode products were formed. More importantly, many of these were chlorinated compounds which severely compromise the 'green' environmental credentials of DES systems. The use of sacrificial materials (e.g. water additions) was also found to minimise the generation of chlorinated products but also interfered with the deposition process. ${ }^{17}$ Similarly, the use of a divided cell ${ }^{16,17}$ avoids some of these issues but such an approach increases energy consumption and is not really suitable for a scaled-up process. Other groups have also observed the generation of $\mathrm{Cl}_{2}$ gas from ethaline DES when carbon ${ }^{18}$ or platinum anodes $^{19}$ were used, which further underlines the issues associated with insoluble anodes. Another approach is to use a non-chloride based DES system but, while choline chloride can be obtained commercially at low cost, other choline salts (e.g. acetate, citrate, nitrate) have a much higher costs or have to be synthesised. ${ }^{2}$ Moreover, the DES formulated from these anions are typically much more viscous and have higher conductivities than for choline chloride. ${ }^{8}$ This results in lower plating rates and poorer throwing power and for this reason chloride-based DES systems are still favoured despite their potential environmental issues.

The preferred option is to use a soluble anode as, under ideal conditions, this should maintain a constant metal ion concentration in the bath and also prevent anodic decomposition of the 
DES. $^{2,3,17}$ Another advantage of soluble anodes is the relatively small anodic overpotential needed to drive the dissolution reaction, and this will reduce the overall energy consumption., ${ }^{2,3}$ In practice, however, it is possible the anodic reaction may produce species in a different valency state from the depositing species and the current efficiency may also differ from the cathodic reaction. ${ }^{20}$ Under these conditions a soluble anode loses most of its effectiveness. Another potential issue is passivation of the anode, which may also cause changes in current efficiency or dissolution valency. ${ }^{20}$ Although most metals-oxides are soluble in deep eutectic solvents ${ }^{6}$ there is a possibility of forming passive salt-films in chloride-containing DES. Finally, the presence of water in the DES may influence the dissolution of the soluble anode by promoting passivation.

Despite such concerns, studies of the anodic behaviour of metals in deep eutectic solvents are relatively rare, but a recent paper by Ryder and co-workers ${ }^{21}$ has examined the dissolution of several metals in pure ethaline and an imidazolium RTIL. For stationary copper electrodes at low applied potentials, active dissolution of copper was observed and it was suggested that this arose from the formation of $\mathrm{CuCl}_{2}^{-}$species. At higher potentials, the anodic current passed through maximum before assuming a limiting current plateau. This active-passive transition was attributed to the formation of an insoluble $\mathrm{CuCl}$ salt film. In the presence of electrode rotation limiting current behaviour was not observed, presumably due to the rapid removal of the $\mathrm{Cu}(\mathrm{I})$ species from the surface. However, the study did not provide any information regarding the dissolution valency, anodic current efficiency or passivation characteristics that are necessary to evaluate soluble anode characteristics. 
There appears to be no other published studies on the anodic behaviour of metals and alloys in DES systems, but a recent study by Forrest ${ }^{22}$ used combined voltammetric and EQCM measurements to investigate deposition and dissolution from a DES containing of $\mathrm{Cu}(\mathrm{I})$ and $\mathrm{Cu}$ (II) chloro-complexes. Interestingly, for the anodic dissolution of copper in the $\mathrm{Cu}$ (II) solution they observed a mass loss that was much higher than anticipated based on the amount of charge passed for a single electron transfer. This amounted to an effective anodic current efficiency greater than $100 \%$. This effect was attributed to a non-electrochemical process, namely the detachment of poorly adherent, unoxidised copper from the surface. ${ }^{22}$ Similar behaviour has been reported in the aqueous corrosion literature and is generally referred to as 'anomalous dissolution' $^{23,24}$

A number of recent reviews ${ }^{2,3,6}$ on the electrodeposition from ILs have stated that one of the key technical issues to be resolved before practical systems can be deployed is fully characterising the anode reactions. However, despite their perceived importance to the development of practical RTIL and DES based plating systems, there have been relatively few investigations of counter electrode (anodic) reactions. Therefore, the major aim of the present study is to examine the feasibility of using soluble copper anodes during the deposition of copper from an ethaline-based DES and to investigate the phenomenon of unusually high anodic current efficiencies. The influence of water adsorption on the performance of practical plating systems has also been identified as an issue requiring further quantification. ${ }^{3}$ A secondary aim was therefore to examine the influence of added water on the anode reaction. While such water additions have minimal influence on the deposit characteristics, and a beneficial effect on solution properties (e.g. viscosity, conductivity), their influence on the characteristics of the soluble anode is unknown. 


\section{Experimental}

'Ethaline' was prepared by mixing choline chloride $\left(\mathrm{C}_{5} \mathrm{H}_{14} \mathrm{NOCl}\right.$, Sigma-Aldrich, > 98\%) and ethylene glycol $\left(\mathrm{C}_{2} \mathrm{H}_{6} \mathrm{O}_{2}\right.$, Sigma-Aldrich, > 99.8\%) in a 1:2 molar ratio without any further purification. The mixture was then heated and stirred at $60^{\circ} \mathrm{C}$ until a transparent melt was formed. As required, $\mathrm{CuCl}$ (Sigma-Aldrich, > 97\%) or $\mathrm{CuCl}_{2} \cdot 2 \mathrm{H}_{2} \mathrm{O}$ (Sigma-Aldrich, > 99\%) were added to the ethaline to formulate plating solutions and reference standards. The ethaline melt had an initial water content of $0.3 \mathrm{wt} \%$ but after adding $0.2 \mathrm{M} \mathrm{CuCl}_{2} \cdot 2 \mathrm{H}_{2} \mathrm{O}$ this increased to $0.9 \mathrm{wt} \%$ due to the hydration of the metal salt. The water content of the DES was measured using a Hybrid Karl-Fischer Titrator (MKH-700, Kem Kyoto Electronics). For some experiments, the concentration of water in the ethaline was adjusted by adding known amounts of DI water, and this was also verified by K-F titration. Spectra of the copper-containing ethaline solutions were recorded using a Varian Cary 5000 UV-VIS-NIR spectrometer over the wavelength range 200 $800 \mathrm{~nm}$. Depending on the copper concentration, a $1 \mathrm{~cm}$ or $0.0125 \mathrm{~cm}$ path length quartz cuvette were used. All reported spectra are corrected against pure ethaline blanks.

For the anodic dissolution experiments, copper disk samples (Alfa-Aesar, 99.999\% purity) were employed as the working electrode. These were polished using 1200 and 2400 grade $\mathrm{SiC}$ paper, rinsed in DI water and then dried with $\mathrm{N}_{2}$. They were then mounted in a PEEK sample holder (Origalys) and the area exposed to the solution was $1.2 \mathrm{~cm}^{2}$. For the voltammetric measurements a $2 \mathrm{~mm}$ diameter platinum disk $\left(0.031 \mathrm{~cm}^{2}\right)$ embedded in PTFE insulator was used as the working electrode. Before use, the Pt electrode was polished with 4000 grade SiC paper, rinsed with DI water and dried. Both the Pt and $\mathrm{Cu}$ samples could be rotated using an EDI101 electrode

rotator and CTV101 speed controller (Radiometer Analytical). The $\mathrm{Cu}$ electrodes were also 
weighed $( \pm 0.1 \mathrm{mg})$ before and after the dissolution experiments in order to determine the dissolution valency and current efficiency.

All experiments were performed in a jacketed two-compartment electrochemical cell where the anode and cathode compartments were separated by a low-porosity glass frit. The working and reference electrodes were mounted in one compartment, while the other contained the counter electrode. In this manner, reaction products formed at the counter electrode could not interfere with the reactions occurring at the working electrode. The volume of solution in each compartment was typically $750 \mathrm{ml}$. A thermostatic bath was used to pump water through the jacket so the cell could be maintained at a temperature of $25{ }^{\circ} \mathrm{C}$. Both cell compartments were sealed from the atmosphere, but no other precautions were taken to exclude water uptake.

Polarisation and anodic dissolution experiments were performed using a potentiostat (PGSTAT101, Metrohm Autolab) in a conventional three-electrode configuration. One cell compartment contained the platinum or copper RDE electrode and a silver wire quasi-reference electrode. To minimise ohmic drop, the Ag reference electrode was placed in a Luggin probe which was positioned within $0.2-0.3 \mathrm{~cm}$ of the RDE surface. It was noticed in preliminary experiments that the copper-containing ethaline solution could corrode the Ag wire reference electrode and contaminate the solution. To minimise this effect, the $\mathrm{Ag}$ wire was subsequently mounted in a fritted glass tube containing pure ethaline before being inserted in the Luggin probe. The counter electrode for the polarisation experiments was a Pt wire; for the anodic dissolution experiments a $\mathrm{Cu}$ wire was used. Polarisation experiments were performed potentiostatically at a scan rate of $5 \mathrm{mV} \mathrm{s}^{-1}$ and with the electrode rotating between 300 and 2000 rpm. The anodic dissolution experiments were performed galvanostatically at current densities of 
$2-12 \mathrm{~mA} \mathrm{~cm}{ }^{-2}$ and rotation rates of 0 to $2000 \mathrm{rpm}$. Experiments on solid copper electrodes indicated that active-passive transitions corresponding to the formation of a $\mathrm{CuCl}$ salt film typically occurred at much higher current densities $\left(>40 \mathrm{~mA} \mathrm{~cm}^{-2}\right)$ so that the present conditions corresponded to the active dissolution of copper.

\section{Results}

In order to understand the basic electrochemical characteristics of the $\mathrm{CuCl}_{2}$-ethaline system some preliminary voltammetric measurements were performed. Figure 1 shows the steady-state voltammogram obtained for $0.20 \mathrm{M} \mathrm{CuCl}_{2}$ in ethaline at a platinum $\mathrm{RDE}(\omega=700 \mathrm{rpm})$ and for varying water content. In the cathodic scan, two distinct limiting current plateaus are visible corresponding to the step-wise reduction of $\mathrm{Cu}(\mathrm{II})$ and $\mathrm{Cu}(\mathrm{I})$ chloro-complexes. ${ }^{7-18}$ This behaviour is similar to that observed for copper in aqueous chloride systems, and reflects the ability of chloride ions to stabilise the $\mathrm{Cu}(\mathrm{I})$ oxidation state. For the anodic scan, there is a stripping peak associated with the formation of $\mathrm{Cu}(\mathrm{I})$ complexes and a final plateau reflecting oxidation back to the original $\mathrm{Cu}(\mathrm{II})$ species. Previous studies ${ }^{9,11,13}$ have shown that that the dominant species formed in the melt is the $\mathrm{CuCl}_{4}{ }^{2-}$ complex and the corresponding reactions are likely to be:

$$
\begin{aligned}
& \mathrm{CuCl}_{4}{ }^{2-}+\mathrm{e}-\Leftrightarrow \mathrm{CuCl}_{2}^{-}+2 \mathrm{Cl}^{-} \\
& \mathrm{CuCl}_{2}{ }^{-}+\mathrm{e}^{-} \Leftrightarrow \mathrm{Cu}+2 \mathrm{Cl}^{-}
\end{aligned}
$$

The current plateaux increased linearly with the square root of the rotation rate indicating that both reduction processes are under mass transport control. Figure 1 also indicates that the 
addition of water increases the limiting current plateaux. This phenomenon was investigated in a previous study and arises mainly from the decrease in viscosity of the DES as the water content is increased. This reduction in viscosity results in an increased diffusivity of the $\mathrm{CuCl}_{4}{ }^{2-}$ and $\mathrm{CuCl}_{2}{ }^{-}$species and therefore higher limiting currents.

Figure 2 shows the UV-Vis spectrum of an ethaline solution after galvanostatic dissolution of a copper anode for varying time periods. For comparison purposes, the UV-Vis spectrum of $\mathrm{CuCl}$ and $\mathrm{CuCl}_{2} \cdot 2 \mathrm{H}_{2} \mathrm{O}$ salts dissolved in ethaline is shown in Figure 3 and 4. The absorption peaks observed reflect the formation of various $\mathrm{Cu}(\mathrm{I})$ and $\mathrm{Cu}(\mathrm{II})$ chloro-complexes. ${ }^{9,11,13,25,26}$ In the case of $\mathrm{CuCl}$ in ethaline, a single peak at $270 \mathrm{~nm}$ is observed which, according to the literature ${ }^{9,13,26}$, corresponds to the species $\mathrm{CuCl}_{2}{ }^{-}$or $\mathrm{CuCl}_{3}{ }^{2-}$. For $\mathrm{CuCl}_{2} \cdot 2 \mathrm{H}_{2} \mathrm{O}$ in ethaline there are peaks at 239, $291 \mathrm{~nm}$ and $405 \mathrm{~nm}$. These peaks are generally attributed to the formation of the $\mathrm{CuCl}_{4}{ }^{2-}$ complex. ${ }^{9,11,13,25,26} \mathrm{~A}$ comparison of Figure 2 and Figure 3 indicates that the product of the anodic dissolution is most likely the $\mathrm{CuCl}_{2}{ }^{-}$species corresponding to the single electron reaction: $\mathrm{Cu}+2 \mathrm{Cl}^{-} \rightarrow \mathrm{CuCl}_{2}^{-}+\mathrm{e}^{-}$. The potential of the copper electrode during anodic dissolution was also monitored and was typically in the range of $0.0-+0.1 \mathrm{~V}$ versus the $\mathrm{Ag}$ wire quasi-reference electrode. A comparison with Figure 1 indicates that this potential is sufficient to allow the formation of $\mathrm{CuCl}_{2}{ }^{-}$but not $\mathrm{CuCl}_{4}{ }^{2-}$.

Figure 2 also indicates that the absorbance peak at $270 \mathrm{~nm}$ increases linearly with dissolution time (charge). This relationship is presented more quantitatively in Figure 5 which shows the concentration of the $\mathrm{Cu}(\mathrm{I})$ complex determined by various means as a function of the anodic charge. The solid line corresponds to the concentration of $\mathrm{Cu}(\mathrm{I})$ species based on a consideration of Faraday's law and assuming a current efficiency of $100 \%$. The triangular symbols represent 
the expected concentration of the $\mathrm{Cu}(\mathrm{I})$ complex based on the measured weight loss of the anode, while the square symbols represent the concentration based on the measured absorbance (Figure 2) and using the measured value of $\varepsilon=3600 \mathrm{M}^{-1} \mathrm{~cm}^{-1}$ for the $270 \mathrm{~nm}$ band. Collectively, the results in Figures 2 - 5 indicate that the only product from the dissolution of copper in pure ethaline is $\mathrm{CuCl}_{2}{ }^{-}$. In Figures 2 and 3 there is a very weak band at $405 \mathrm{~nm}$ indicating the possible presence of trace amounts of $\mathrm{CuCl}_{4}{ }^{2-}$ but it is likely that this has formed via disproportionation or oxidation of the $\mathrm{CuCl}_{2}{ }^{-}$complex. ${ }^{9}$ Note that these anodic dissolution experiments could not be performed in concentrated $\mathrm{CuCl}_{2}$ containing solutions due to the presence of strong, overlapping adsorption bands.

A simple and convenient way of measuring the characteristics of the anodic dissolution process is to use Faraday's law to relate the mass loss, $\Delta m$, associated with the passage of a known amount of charge. ${ }^{27}$ If the dissolution valency, $n$, is known the current efficiency, $\varepsilon$, of the process can then be assessed. Values of $\varepsilon=100 \%$ are common in metal dissolution but can be lower due to the occurrence of a competing anodic reaction (e.g. $\mathrm{O}_{2}$ evolution). In rare cases, values of $\varepsilon>100 \%$ have been measured indicating a mass loss greater than that expected from Faraday's law. $^{23,24}$ In the electrochemical polishing, machining and corrosion literature ${ }^{23,24,27}$ it is common to report data in terms of the 'apparent' dissolution valency, $n$ '. Clearly, only in the case of $\varepsilon=100 \%$ does $n^{\prime}=n$ and a current efficiency exceeding $100 \%$ can also be interpreted in terms of an apparent dissolution valency of $n '<n$.

Figure 6 shows the apparent dissolution valency of copper electrode determined gravimetrically as a function of the applied current density. These experiments were performed in a solution containing $0.2 \mathrm{M} \mathrm{CuCl}_{2}$ in ethaline with the electrode either stationary or rotating at $700 \mathrm{rpm}$. 
Interestingly, the apparent dissolution valency is $n^{\prime}<1$ even though earlier experiments (Figure 5) in pure ethaline suggested that the anodic dissolution process is $\mathrm{Cu}+2 \mathrm{Cl}^{-} \rightarrow \mathrm{CuCl}_{2}{ }^{-}+\mathrm{e}^{-}$with $n^{\prime}=n=1$. The apparent dissolution valency was smallest at low applied current densities and when the electrode was rotated. Only for relatively high applied current densities $\left(>10 \mathrm{~mA} \mathrm{~cm}^{-2}\right)$ at stationary electrodes did the apparent dissolution valency approach the expected value of unity. In order to explore this phenomenon in more detail, additional experiments were performed where the current density was fixed at $2.85 \mathrm{~mA} \mathrm{~cm}^{-2}$ and the $\mathrm{CuCl}_{2}$ concentration was varied from 0 to $0.20 \mathrm{M}$ (Figure 7). As before, the experiments were performed with the electrode either stationary or rotating at $700 \mathrm{rpm}$. In pure ethaline, a dissolution valency of unity was determined gravimetrically, which agrees with the results shown in Figure 5. Recently, a value of $n=0.97$ was reported ${ }^{28}$ for the dissolution of copper in pure ethaline which is also in good agreement with our findings. However, as the $\mathrm{CuCl}_{2}$ concentration was increased the apparent dissolution valency decreased significantly, and this was observed for both stationary and rotating electrodes. As before, the apparent dissolution valency was always higher for stationary electrodes than for rotating ones, indicating the importance of mass transport effects.

The final experiments undertaken involved examining the effect of electrode rotation on the apparent dissolution valency (Figure 8). These were performed at a current density of $2.85 \mathrm{~mA}$ $\mathrm{cm}^{-2}$ in pure ethaline or in an ethaline solution containing $0.20 \mathrm{M} \mathrm{CuCl}_{2}$. The apparent valency is plotted as a function of $\omega^{1 / 2}$ in order to examine the possible importance of mass transport effects. Figure 8 indicates that the dissolution valency in pure ethaline is always unity and shows no dependence on the rotation rate. In contrast, in the presence of $0.2 \mathrm{M} \mathrm{CuCl}_{2}$ a steady reduction in the apparent dissolution valency with rotation rate is observed. This agrees with the earlier 
findings and again indicates the importance of mass transport effects in determining the dissolution behaviour.

Collectively, the results in Figures $6-8$ show an apparent dissolution valency less than unity (or, equivalently, $\varepsilon>100 \%$ ) which is indicative of a mass loss greater than that expected from Faraday's law. If dissolution was occurring by the formation of both $\mathrm{Cu}(\mathrm{I})$ and $\mathrm{Cu}(\mathrm{II})$ complexes then a value of $1<n^{\prime}<2$ might be expected. Similarly, if a side reaction was occurring in parallel with anodic dissolution so that $\varepsilon<100 \%$, a value of $n^{\prime}>1$ might be anticipated. However, an apparent dissolution valency of less than unity must be indicative of a more complex process involving either a corrosion reaction occurring in parallel, or some other nonelectrochemical process. As noted in the Introduction, this phenomenon has been observed ${ }^{22}$ in DES systems but the exact cause has not been established.

\section{Discussion}

In attempting to explain the observed results, it is instructive to review some of the previous reports of 'anomalous dissolution'. Many of these have appeared in the corrosion literature, where large discrepancies between the measured mass loss and the corrosion rate have occasionally been encountered. The literature related to this effect been extensively

reviewed. $^{23,24}$ One possible explanation for this effect is electrode disintegration ('chunk' effect) where pieces of the metal are detached from the electrode in an essentially non-electrochemical process. In this scenario, the mass loss is greater than expected from the actual anodic charge. For example, intergranular corrosion might allow for the detachment of individual grains where the majority of the atoms are not oxidised. Similarly, highly dendritic deposits might be undercut 
at their base by localised corrosion reactions leading to the dislodgement of large metallic particles. ${ }^{22}$ Such metallic residues have been reported ${ }^{23}$ in some corroding systems, but in many instances dissolution occurs without their presence.

An alternative explanation is that a corrosion reaction is occurring in parallel with anodic dissolution. ${ }^{27}$ Because this is an internal current process, it produces additional metal loss independent of the externally measured anodic charge. While this mechanism is plausible, it has rarely been considered in studies of 'anomalous dissolution'. Most reported examples ${ }^{29-31}$ have been observed during high rate (i.e. transpassive) dissolution of metals such as $\mathrm{Fe}$ and $\mathrm{Ni}$ in aqueous electrolytes. In some cases current efficiencies of $\varepsilon>100 \%$ were observed indicating a mass loss higher than expected based on the charge passed. It was subsequently proposed that this was due to the occurrence of a chemical (corrosion) reaction on the anode surface. For example, the following corrosion reaction was proposed to occur during the anodic dissolution of iron in chlorate solutions:

$$
2 \mathrm{Fe}+\mathrm{ClO}_{3}^{-}+6 \mathrm{H}^{+} \rightarrow 2 \mathrm{Fe}^{3+}+\mathrm{Cl}^{-}+3 \mathrm{H}_{2} \mathrm{O}
$$

The rate of this reaction was quantified by the accumulation of $\mathrm{Cl}^{-}$ions in the electrolyte, and a subsequent mass balance calculation indicated that it could readily account for the apparent current efficiency of $\varepsilon>100 \% .{ }^{29}$ Additionally, no metallic debris was observed that might have arisen from electrode disintegration. ${ }^{30}$

Now that a possible explanation for the observed dissolution behaviour has been identified, it is necessary to examine which corrosion reactions might plausibly occur at the anode. The corrosion rate of copper in oxygen-containing pure ethaline under similar hydrodynamic 
conditions (RDE at $\omega=1000 \mathrm{rpm}$ ) has been determined to be $j_{\text {corr }}=0.02 \mathrm{~mA} \mathrm{~cm}{ }^{-2}$ at $25{ }^{\circ} \mathrm{C} .{ }^{28}$

This is more than two orders of magnitude lower than the corrosion rates measured in the present study, which indicates that copper corrosion by dissolved $\mathrm{O}_{2}$ is not responsible for our

observations. However, in the presence of $\mathrm{Cu}^{2+}$, the corrosion rate is significantly higher and can arise from the comproportionation reaction:

$$
\mathrm{CuCl}_{4}^{2-}+\mathrm{Cu} \rightarrow 2 \mathrm{CuCl}_{2}^{-}
$$

The thermodynamic feasibility of this reaction can be established from an analysis of the standard (formal) electrode potentials, $E^{0}$, for reactions [1] and [2]. The measurement of standard potentials in ethaline-based DES are complicated by electrode irreversibilities, but values of $E^{0}\left(\mathrm{Cu}^{2+} / \mathrm{Cu}\right)=+0.58 \mathrm{~V}$ and $E^{0}\left(\mathrm{Cu}^{+} / \mathrm{Cu}\right)=-0.22 \mathrm{~V}$ have been estimated. ${ }^{5,9}$ These values can be used to calculate a Gibbs free energy of $\Delta G^{0}=-77 \mathrm{~kJ} \mathrm{~mol}^{-1}$ for reaction [4], indicating that comproportionation is spontaneous under standard conditions.

The plausibility of this mechanism can be verified by examining Figure 9 which indicates that under open circuit conditions the anodic dissolution processes to form $\mathrm{CuCl}_{2}{ }^{-}$can couple with the cathodic process involving the reduction $\mathrm{CuCl}_{4}{ }^{2-}$. The resulting position of the mixed potential, $E_{\text {corr }}$, and the associated corrosion current, $i_{\text {corr }}$, are also shown in Figure 9. Most importantly, the cathodic reaction is under mass transport control so that the corrosion rate will be controlled purely by the cathodic limiting current $\left(i . e . j_{\text {corr }}=j_{\text {lim }}\right)$. This can be shown more clearly as an Evans diagram (Figure 10) which displays schematically the anodic and cathodic partial current densities and the position of $E_{\text {corr }}$ and $j_{\text {corr }}$. 
In a previous study ${ }^{32}$ it was demonstrated that this comproportionation reaction occurs in the offtime during the pulse plating of copper from a $\mathrm{CuCl}_{2}$-ethaline electrolyte. This effect is responsible for the low cathodic current efficiency observed under pulse conditions, and a similar effect has been reported in an aqueous chloride system. ${ }^{33}$ Comproportionation reactions involving copper have been encountered in others ILs ${ }^{34}$, and it is often used to prepare soluble $\mathrm{Cu}(\mathrm{I})$ complexes by reacting $\mathrm{Cu}(\mathrm{II})$ complexes with $\mathrm{Cu}^{35}$ In aqueous systems the importance of this reaction is well known, and $\mathrm{CuCl}_{2}$ solutions are routinely used to etch copper for printed circuit board fabrication. $^{36}$

If it is assumed that comproportionation is the dominant corrosion reaction, and that it is under mass-transport control, an expression relating the apparent dissolution valency to the magnitude of $j_{\text {corr }}$ can be derived. The proposed mechanism is shown schematically in Figure 11. This indicates that, during the anodic dissolution of copper, the electrons generated can flow through the external circuit or be consumed by the reduction of $\mathrm{CuCl}_{4}{ }^{2-}$ at the electrode surface. It then follows that:

$$
j_{\text {app }}+j_{\text {corr }}=j_{\text {a }}
$$

where $j_{\text {app }}$ is the applied current density, $i_{\mathrm{a}}$ is the anodic dissolution current density and $j_{\text {corr }}$ is the corrosion current density. This relationship is also shown schematically on the Evans diagram (Figure 10). By applying Faraday's law to the anodic current density we obtain:

$$
j_{a}=\frac{n^{\prime} F \Delta m}{t M A}
$$

where $n$ ' is the apparent valency, $F$ is the Faraday constant, $\Delta m$ is the observed mass loss, $M$ is the molar mass, $A$ is the electrode area and $t$ is the dissolution time. Then by substituting 
equation [6] into [5] and rearranging, the following expression for the apparent dissolution valency is obtained:

$$
n^{\prime}=\frac{\left(j_{\mathrm{corr}}+j_{\mathrm{app}}\right) t M A}{\Delta m F}
$$

Clearly, in the case where corrosion is significant equation [7] predicts that $n^{\prime}<n$, and only when $j_{\text {corr }}=0$ is a dissolution valency of $n^{\prime}=n$ obtained. Moreover, with the condition of cathodic mass transport control we can write:

$$
j_{\text {corr }}=j_{\text {lim }}=\frac{n_{c} F D c}{\delta}
$$

where $n_{\mathrm{c}}$ is the number of electrons transferred in the cathodic process, $\delta$ is the diffusion layer thickness, and $D$ and $c$ are the diffusion coefficient and bulk concentration of the $\mathrm{CuCl}_{4}{ }^{2-} \mathrm{species}$, respectively. This suggests that if $j_{\text {lim }}$ is raised by increasing $c$ or $D$ (or by reducing $\delta$ ) then $j_{\text {corr }}$ is also increased and this results in a lower apparent dissolution valency.

Equation [7] can then be used to extract $j_{\text {corr }}$ from the apparent dissolution valency data. Figure 12 , for example, shows the $j_{\text {corr }}$ data extracted in this manner and plotted against $\omega^{1 / 2}$. The linear behaviour strongly suggests that the $j_{\text {corr }}$ is under mass transport control - as is expected from the model. This Levich-like behaviour is observed at all water contents. Similarly, $j_{\text {corr }}$ can be extracted from the data and plotted against the $\mathrm{Cu}(\mathrm{II})$ concentration (Figure 13). Once again, these plots are highly linear at all electrode rotation rates and this is as expected based on the relationship between $j_{\text {corr }}$ and $j_{\lim }$ and $c$.

A final test of the proposed corrosion model is to directly compare the measured limiting currents, $j_{\text {lim }}$, (Figure 1 ) with the values of $j_{\text {corr }}$ extracted from the dissolution valency data under 
identical conditions $\left(\omega=700 \mathrm{rpm}, 0.2 \mathrm{M} \mathrm{CuCl}_{2}\right.$ and $1-15 \mathrm{wt} \%$ water). As noted earlier, water increases the diffusivity of the $\mathrm{CuCl}_{4}{ }^{2-}$ species and this result in an increase in the limiting current (Figure 1). Consequently, water additions should increase the corrosion rate and reduce the apparent dissolution valency. In Table 1 the $j_{\text {corr }}$ obtained from the dissolution valency data is compared with the $j_{\lim }$ data from Figure 1 . There is good agreement (typically within 5\%) indicating that the model explains the data well. The effect of water on the rate of comproportionation in the $\mathrm{CuCl}_{2}$-ethaline system was recently explored by $\mathrm{Zhou}$ and coworkers. ${ }^{26}$ They also found that the rate increased with water content and attributed this to the enhanced mass transfer of the $\mathrm{Cu}(\mathrm{II})$ species.

In summary, the proposed model explains quantitatively the dissolution of copper in an ethaline DES. In particular, the observed dependency of the apparent dissolution valency on the electrode rotation rate, $\mathrm{CuCl}_{4}{ }^{2-}$ concentration, and the water content can all be rationalised by the existence of a comproportionation reaction that is under mass-transport control. Both the model and experimental data indicate that the expected valency $(n=1)$ can only be attained when the rate of corrosion is negligible compared to the applied dissolution current. Corrosion by comproportionation can be minimised by using a low concentration of $\mathrm{Cu}(\mathrm{II})$ species, a low water content and minimal agitation but will always be present to some extent. In order to explain the results it was not necessary to invoke an anode disintegration type mechanism. If this were the dominant process it is unlikely that the mass loss would exhibit such a strong linear dependence on $\omega^{1 / 2}$ or concentration.

It should be noted that the corrosion effects observed for the $\mathrm{CuCl}_{2}$-ethaline system are possible for other IL and DES systems. For example, the $\mathrm{FeCl}_{3}$-reline system has been used to deposit 
iron films using inert anodes ${ }^{37}$, but if soluble iron or steel anodes are used they will invariably corrode by the comproportionation reaction: $2 \mathrm{FeCl}_{4}{ }^{-}+\mathrm{Fe}+4 \mathrm{Cl}^{-} \rightarrow 3 \mathrm{FeCl}_{4}{ }^{2-} \cdot{ }^{38}$ This effect is also seen during the discharge of all-iron redox-batteries employing aqueous ${ }^{39}$ or DES $^{40}$ electrolytes where $\mathrm{Fe}(\mathrm{III})$ species in the cathode compartment can crossover through the membrane and etch the iron anode. Type-II eutectics containing $\mathrm{CrCl}_{3} \cdot 6 \mathrm{H}_{2} \mathrm{O}$ in choline chloride have also shown susceptibility to anode corrosion. In a recent technical report ${ }^{41}$ it was noted that that the anodic current efficiency often exceeded $100 \%$. This was explained by assuming that dissolution can occur via a $\mathrm{Cr}$ (II) complex rather than the expected $\mathrm{Cr}(\mathrm{III})$ species. However, this suggestion cannot explain the apparent current efficiencies in excess of $150 \%$ that were observed at low applied current densities. A more likely explanation is that the soluble chromium anode reacts with $\mathrm{Cr}(\mathrm{III})$ complexes via a comproportionation reaction producing $\mathrm{Cr}(\mathrm{II})$ species. Other reports ${ }^{42}$ of chromium deposition from type-II eutectics have also indicated substantial corrosion of the $\mathrm{Cr}$ anode in the absence of any applied current. More recently, comproportionation reactions effects involving the anode and cathode have also been encountered during niobium deposition from various ILs. ${ }^{43}$

Finally, it should be noted that the occurrence of comproportionation reaction poses some issues for the use of soluble anodes in many DES and IL systems. For example, corrosion by comproportionation will significantly influence the current efficiency of the anode reaction. The corrosion rate will depend strongly on experimental conditions (e.g. concentration of species, agitation and applied current density) and therefore the overall dissolution rate may not be easily predictable or stable. More importantly, the comproportionation reaction will introduce species into the plating solution in a different (i.e. lower) oxidation state (for example as $\mathrm{Cr}(\mathrm{II}), \mathrm{Cu}(\mathrm{I})$ or $\mathrm{Fe}(\mathrm{II})$ ) while depleting the solution of the higher-valency species that normally deposit at the 
cathode. These lower-valency species may undergo further reactions in solution (e.g. disproportionation) or at the cathode. ${ }^{43}$ In the latter case the current efficiency for deposition will also be altered. Under such conditions the use of soluble anodes is questionable and is likely to complicate rather than simplify control of the bath chemistry.

\section{Conclusion}

This study has examined the nature of the dissolution reaction occurring at soluble copper anodes during the electrodeposition of copper from an ethaline-based DES. For dissolution in pure ethaline, UV-Vis spectroscopy and electrochemical measurements indicated that the dominant anodic species produced was $\mathrm{CuCl}_{2}^{-}$. The current efficiency of the anodic process determined gravimetrically was $100 \%$ and the dissolution valency was one. However, in the presence of $\mathrm{Cu}$ (II) complexes the apparent dissolution valency was typically less than unity, corresponding to an observed mass loss greater than that expected from Faraday's law. The apparent dissolution valency showed a marked dependence on the electrode rotation rate, $\mathrm{Cu}(\mathrm{II})$ concentration and water content, indicating the likely importance of mass transport limitations. Collectively, these observations suggested that a corrosion process was occurring in parallel with normal anodic dissolution.

A model that allows for the influence of a corrosion reaction on the apparent dissolution valency was then developed. This model assumes that the corrosion process involves the comproportionation reaction: $\mathrm{CuCl}_{4}{ }^{2-}+\mathrm{Cu} \rightarrow 2 \mathrm{CuCl}_{2}$. This process is thermodynamically feasible in the DES and had also been observed in an earlier study involving pulse plating of 
copper. In addition, voltammetric experiments indicated that the reaction rate would be controlled by the mass transfer of the $\mathrm{Cu}(\mathrm{II})$ species to the surface. This model was able to quantitatively account for the effect of all major variables on the apparent dissolution valency including $\mathrm{Cu}(\mathrm{II})$ concentration, hydrodynamic conditions and water content. The occurrence of such comproportionation reactions is possible in other ILs and DESs and a number of susceptible systems have been identified. Finally, some of the practical issues associated with the occurrence of such corrosion reactions have been discussed. In general, these will negate many of the inherent advantages of soluble anodes and increase the complexity of the bath chemistry. 


\section{Acknowledgements}

P. Valverde would like to acknowledge the Secretariat of Higher Education, Science, Technology, and Innovation of Ecuador (SENESCYT) for funding this work. 


\section{References}

1. A.P. Abbott, G. Capper, D.L. Davies, R. Rasheed and V. Tambyrajah, Chem. Commun., 70 (2003).

2. F. Endres, D. MacFarlane and A. Abbott, Electrodeposition from Ionic Liquids, $2^{\text {nd }}$ edition, Wiley-VCH, Weinheim (2017).

3. A.P. Abbott, G. Frisch and K.S. Ryder, Annu. Rev. Mater. Res., 43, 335 (2013).

4. L.I.N. Tome, V. Baiao, W. da Silva and C.M.A. Brett, Appl. Mater. Today, 10, 30 (2018).

5. E.L. Smith, A.P. Abbott and K.S. Ryder, Chem. Rev., 114, 11060 (2014).

6. A.P. Abbott and K.J. McKenzie, Phys. Chem. Chem. Phys., 8, 4265 (2006).

7. A.P. Abbott, K.S. Ryder and U. Konig, Trans. IMF, 86, 196 (2008).

8. R. Bernasconi, M. Zebarjadi and L. Magagnin, J. Electroanal. Chem. 758, 163 (2015).

9. A. Mandroyan, M. Mourad-Mahmoud, M-L. Doche and J-Y. Hihn, Ultrason. Sonochem., 21, 2010 (2014).

10. B.G. Pollet, J-Y. Hihn and T.J. Mason, Electrochim. Acta., 53, 4248 (2008).

11. A.P. Abbott, K. El Ttaib, G. Frisch, K.J. McKenzie and K.S. Ryder, Phys. Chem. Chem. Phys., 11, 4269 (2009).

12. T. Tsuda, L.E. Boyd, S. Kuwabata and C.L. Hussey, J. Electrochem. Soc., 157, F96 (2010).

13. D. Lloyd, T. Vainikka, L. Murtomaki, K. Kontturi and E. Ahlberg, Electrochim. Acta., 56, $4942(2011)$.

14. S. Ghosh and S. Roy, Surf. Coat. Technol., 238, 165 (2014).

15. C.L. Hussey, ECS Trans., 64, 3 (2014).

16. P. Valverde, T.A. Green and S. Roy, ECS Trans., 77, 859 (2017). 
17. K. Haerens, E. Matthijs, K. Binnemans and B. Van der Bruggen, Green Chem., 11, 1357 (2009).

18. J. Ru, Y. Hua, D. Wang, C. Xu, J. Li, Y. Li, Z. Zhou and K. Gong, Electrochim. Acta., 186, 455 (2015).

19. D. Yue, Y. Jia, Y. Yao, J. Sun and Y. Jing, Electrochim. Acta., 65, 30 (2012).

20. Y.D. Gamburg and G. Zangari, Theory and Practice of Metal Electrodeposition, Springer, New York (2011).

21. A.P. Abbott, G. Frisch, J. Hartley, W.O. Karim and K.S. Ryder, Progress in Natural Science: Materials International, 25, 595 (2015).

22. G.C.H. Forrest, Electrochemistry and Galvanic Deposition of Group 10 \& 11 Transition Metals Using Deep Eutectic Solvents, PhD Thesis, University of Leicester, 2014.

23. D.M. Drazic and J.P. Popic, J. Serb. Chem. Soc., 70, 489 (2005).

24. W.E. James, in Advances in Corrosion Science and Technology, Vol. 4, M. G. Fontana and R. W. Staehle, Editors, Plenum Press, New York (1974).

25. P. De Vreese, N.R. Brooks, K. Van Hecke, L. Van Meervelt, E. Matthijs, K. Binnemans and R. Van Deun, Inorg. Chem., 51, 4972 (2012).

26. Y. Su, J. Liu, R. Wang, S. Aisa, X. Cao, S. Li, B. Wang and Q. Zhou, J. Electrochem. Soc., 165, H78 (2018).

27. M. Datta, IBM. J. Res. Develop., 37, 207 (1993).

28. M-L. Doche, A. Mandroyan, M. Mourad-Mahmoud, V. Moutarlier and J-Y. Hihn, Chemical Engineering \& Processing: Process Intensification, 121, 90 (2017).

29. M. Datta and D. Landolt, Electrochim Acta., 25, 1263 (1980).

30. M. Datta and D. Landolt, Corros. Sci., 13, 187 (1973). 
31. K-W. Chen and D-T. Chin, J. Electrochem. Soc., 121, 191 (1974).

32. T.A Green, X. Su and S. Roy, ECS Trans., 77, 1247 (2017).

33. C.W. Yeow and D.B. Hibbert, J. Electrochem. Soc., 130, 786 (1983).

34. S. Vanderaspoilden, J. Christophe, Th. Doneux and C. Buess-Herman, Electrochim. Acta., 162, $156(2015)$.

35. K. Murase, K. Nitta, T. Hirato and Y. Awakura, J. Appl. Electrochem., 31, 1089 (2001).

36. M. Georgiadou and R. Alkire, J. Electrochem. Soc., 140, 1340 (1993).

37. R. Bock and S.-E. Wulf, Trans. IMF, 87, 28 (2009).

38. D. Lloyd, T. Vainikka, M. Ronkainen and K. Kontturi, Electrochim. Acta., 109, 843 (2013).

39. L.W. Hruska and R.F. Savinell, J. Electrochem. Soc., 128, 18 (1981).

40. M.A. Miller, J.S. Wainright and R.F. Savinell , J. Electrochem. Soc., 164, A796 (2017).

41. J. Fischer, E. Nagel and M. Mann, 'Investigations concerning chromium plating from electrolytes containing chromium-III chloride and ionic liquid', Report No. 120808 JKF, University of North Dakota (2012).

42. P. Verpoort and E.D. Gonzalez, Joint Workshop on Ionic Liquids at Interfaces, 3 - $5^{\text {th }}$ October 2015, Belek, Turkey.

43. E. Freydina and J.G. Abbot, ECS Trans., 75, 639 (2016). 


\begin{tabular}{|c|c|c|}
\hline $\begin{array}{c}\mathrm{H}_{2} \mathrm{O} \text { content } \\
(\mathrm{wt} \%)\end{array}$ & $\begin{array}{c}j_{\text {corr }} \\
\left(\mathrm{mA} \mathbf{c m}^{-2}\right)\end{array}$ & $\begin{array}{c}j_{\lim } \\
\left.(\mathrm{mA} \mathrm{cm})^{-2}\right)\end{array}$ \\
\hline 1 & 2.69 & 2.82 \\
\hline 3 & 4.30 & 4.32 \\
\hline 6 & 5.66 & 4.44 \\
\hline 10 & 6.70 & 6.39 \\
\hline 15 & 8.81 & 9.11 \\
\hline
\end{tabular}

Table 1: Comparison of $j_{\text {corr }}$ extracted from the dissolution valency data and $j_{\text {lim }}$ measured for the reduction of $\mathrm{CuCl}_{4}{ }^{2-}$ species at various water contents. The electrode rotation rate was $700 \mathrm{rpm}$ and $\mathrm{CuCl}_{2}=0.20 \mathrm{M}$. 


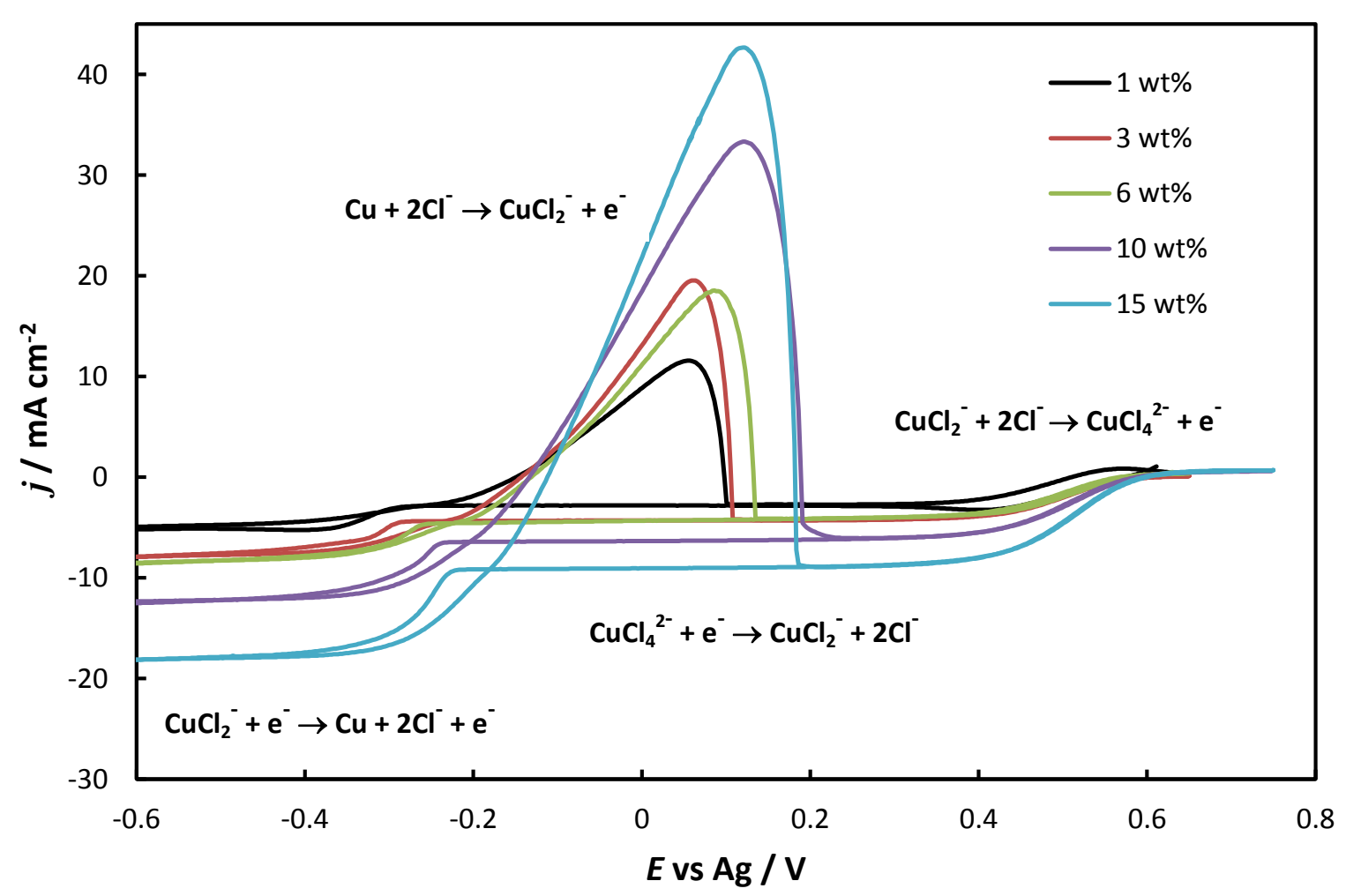

Figure 1: Steady-state voltammogram of a solution of $0.20 \mathrm{M} \mathrm{CuCl}_{2}$ in ethaline with different water content $\left(1-15 \mathrm{wt} \% \mathrm{H}_{2} \mathrm{O}\right)$. The electrode rotation rate was $\omega=700 \mathrm{rpm}$. 


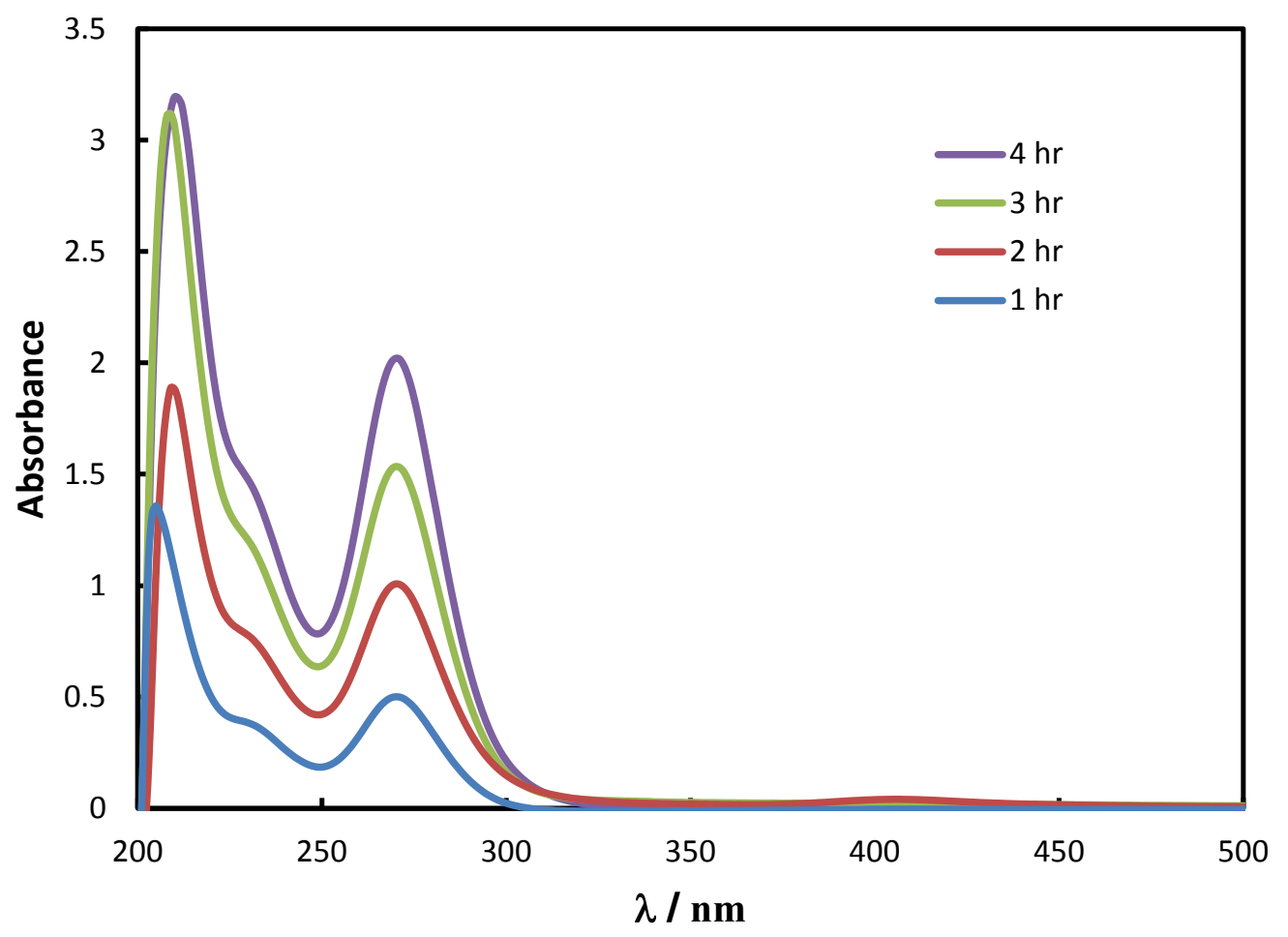

Figure 2: UV-Vis spectrum (1 $\mathrm{cm}$ cuvette) of the anode compartment solution after anodic dissolution of $\mathrm{Cu}$ in pure ethaline. The current density was $2.5 \mathrm{~mA} \mathrm{~cm}^{-2}$ and the duration from 1 to 4 hours. 


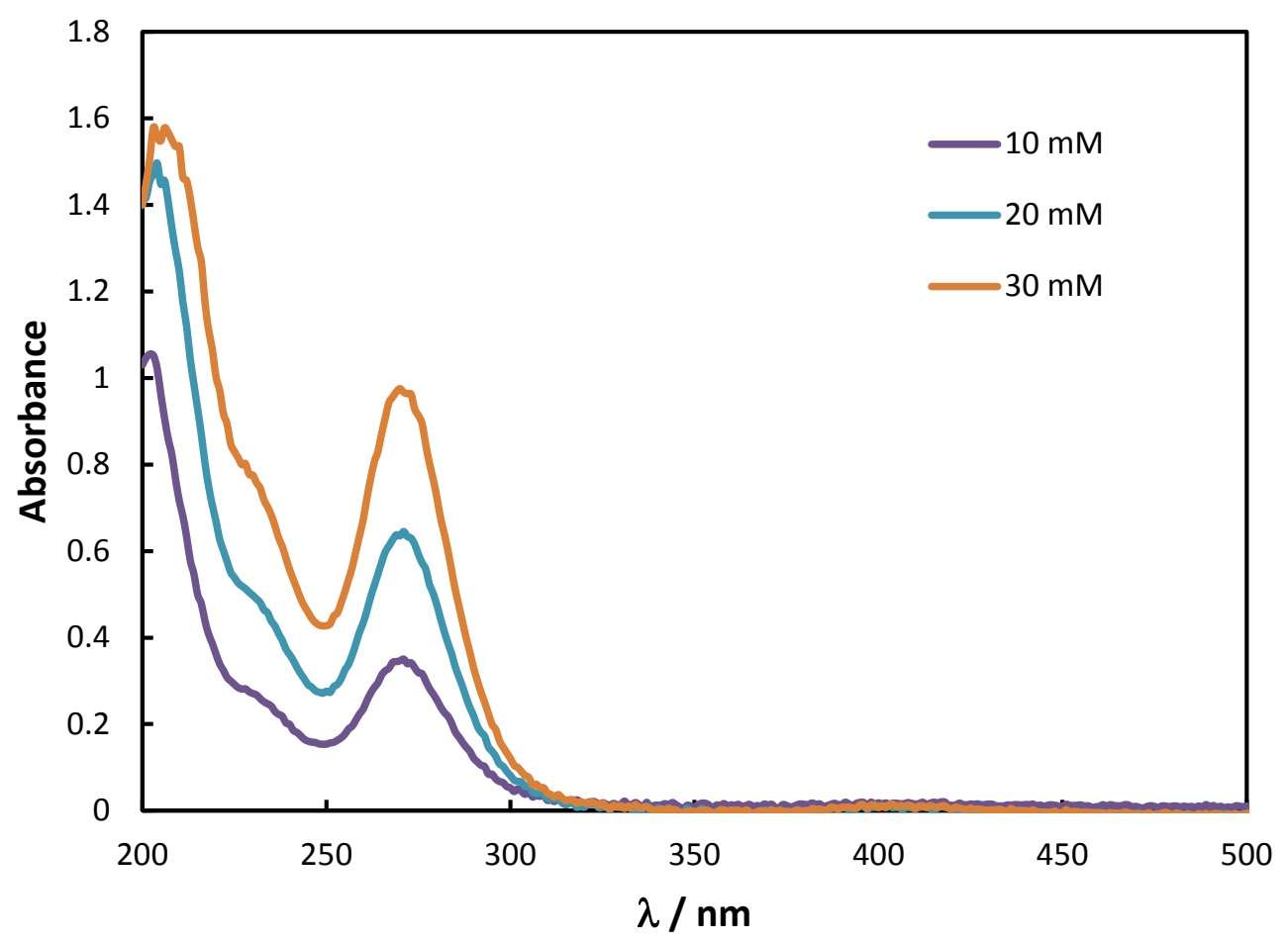

Figure 3: UV-Vis spectrum $(0.0125 \mathrm{~cm}$ cuvette $)$ at various concentrations $(10,20$ and $30 \mathrm{mM})$ of $\mathrm{CuCl}$ dissolved in pure ethaline. 


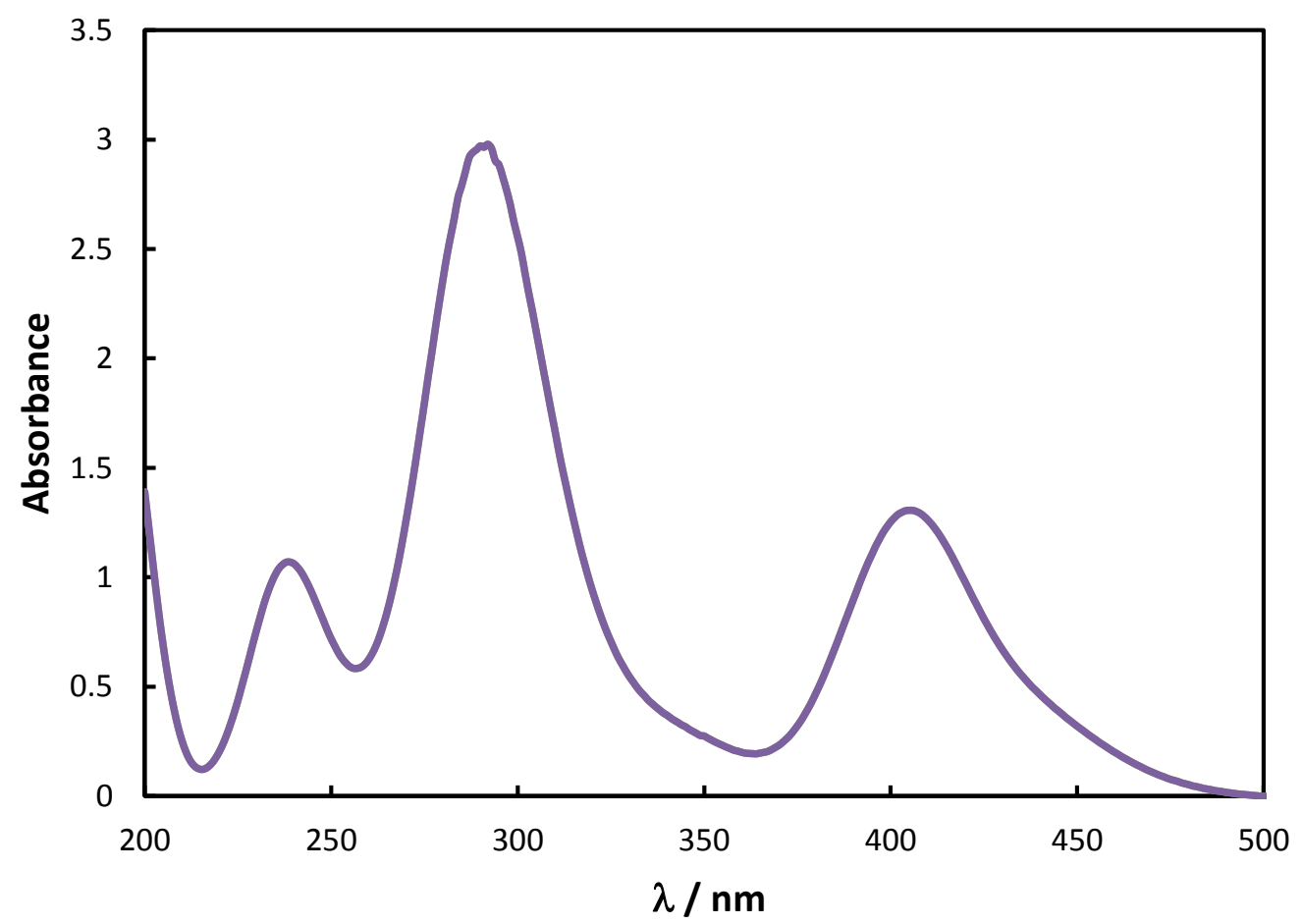

Figure 4: UV-Vis spectrum $(0.0125 \mathrm{~cm}$ cuvette $)$ of $50 \mathrm{mM} \mathrm{CuCl} 2.2 \mathrm{H}_{2} \mathrm{O}$ dissolved in pure ethaline. 


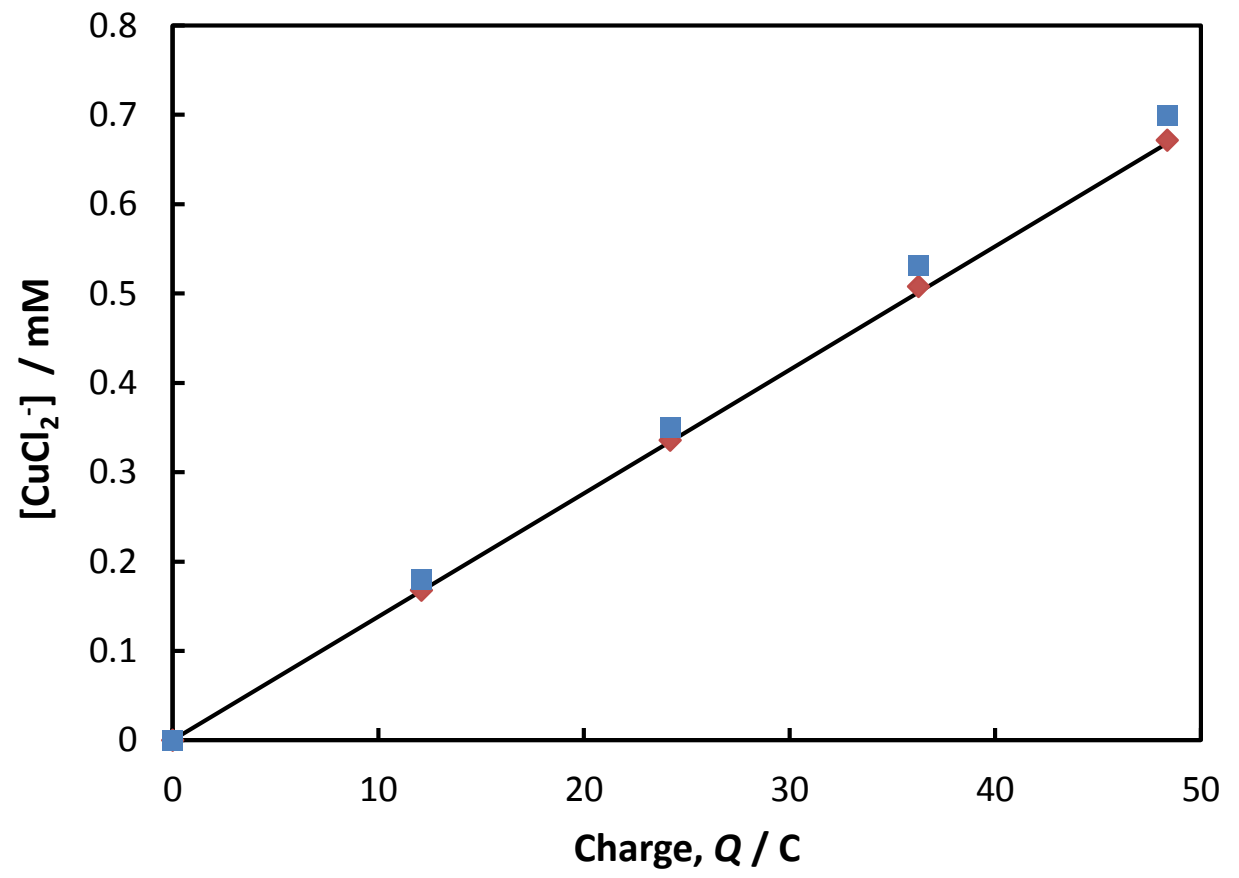

Figure 5: Plot of $\mathrm{CuCl}_{2}{ }^{-}$concentration versus anodic charge, $Q$ in pure ethaline. (-) symbol show the concentration inferred from the absorbance data at $270 \mathrm{~nm}$ in Figure 2. (•) symbol show the concentration based on the mass loss of the anode. The solid line indicates the expected value from Faraday's law with $n=1$. 


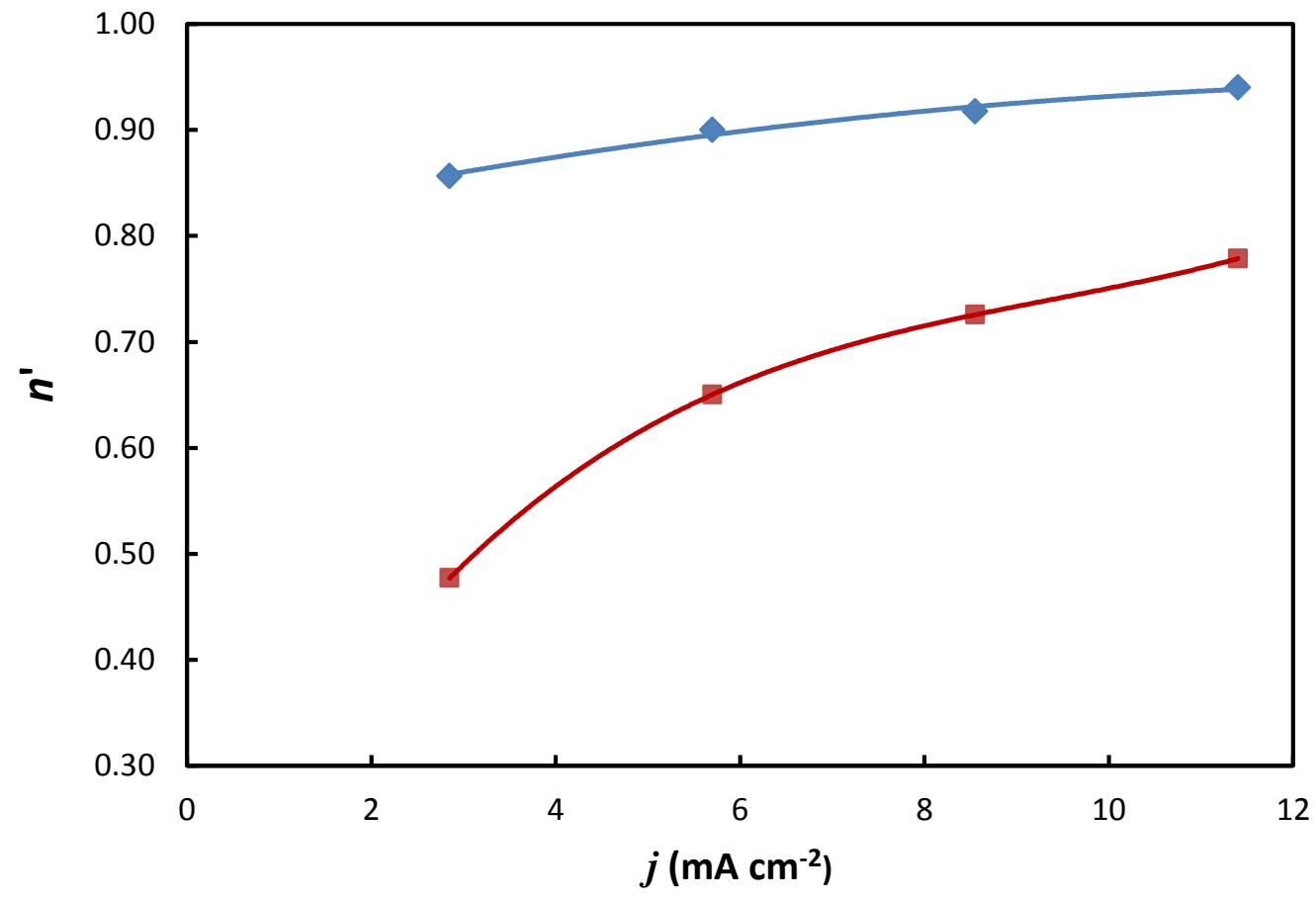

Figure 6: The apparent dissolution valency, $n$, of the copper electrode in $0.20 \mathrm{M} \mathrm{CuCl}_{2}$ in ethaline containing $1 \mathrm{wt} \% \mathrm{H}_{2} \mathrm{O}$ as a function of the applied current density and electrode rotation rate. $(\diamond) \omega=0 \mathrm{rpm}(\bullet) \omega=700 \mathrm{rpm}$. 


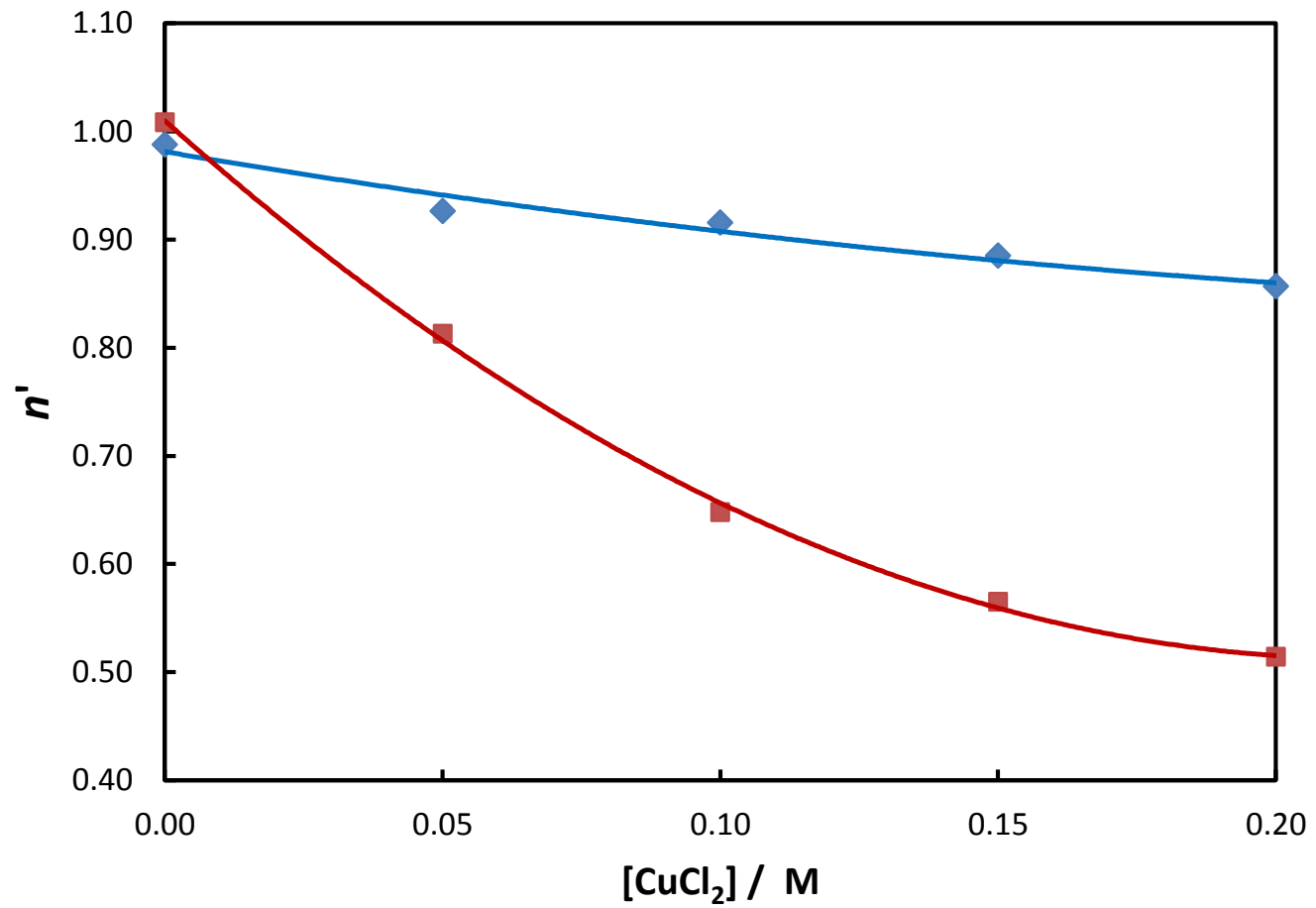

Figure 7: The apparent dissolution valency, $n$ ', of the copper electrode at $2.85 \mathrm{~mA} \mathrm{~cm}^{-2}$ as a function of the $\mathrm{Cu}(\mathrm{II})$ concentration and electrode rotation rate in an ethaline solution containing $1 \mathrm{wt} \% \mathrm{H}_{2} \mathrm{O} .(\diamond) \omega=0 \mathrm{rpm}(\bullet) \omega=700 \mathrm{rpm}$. 


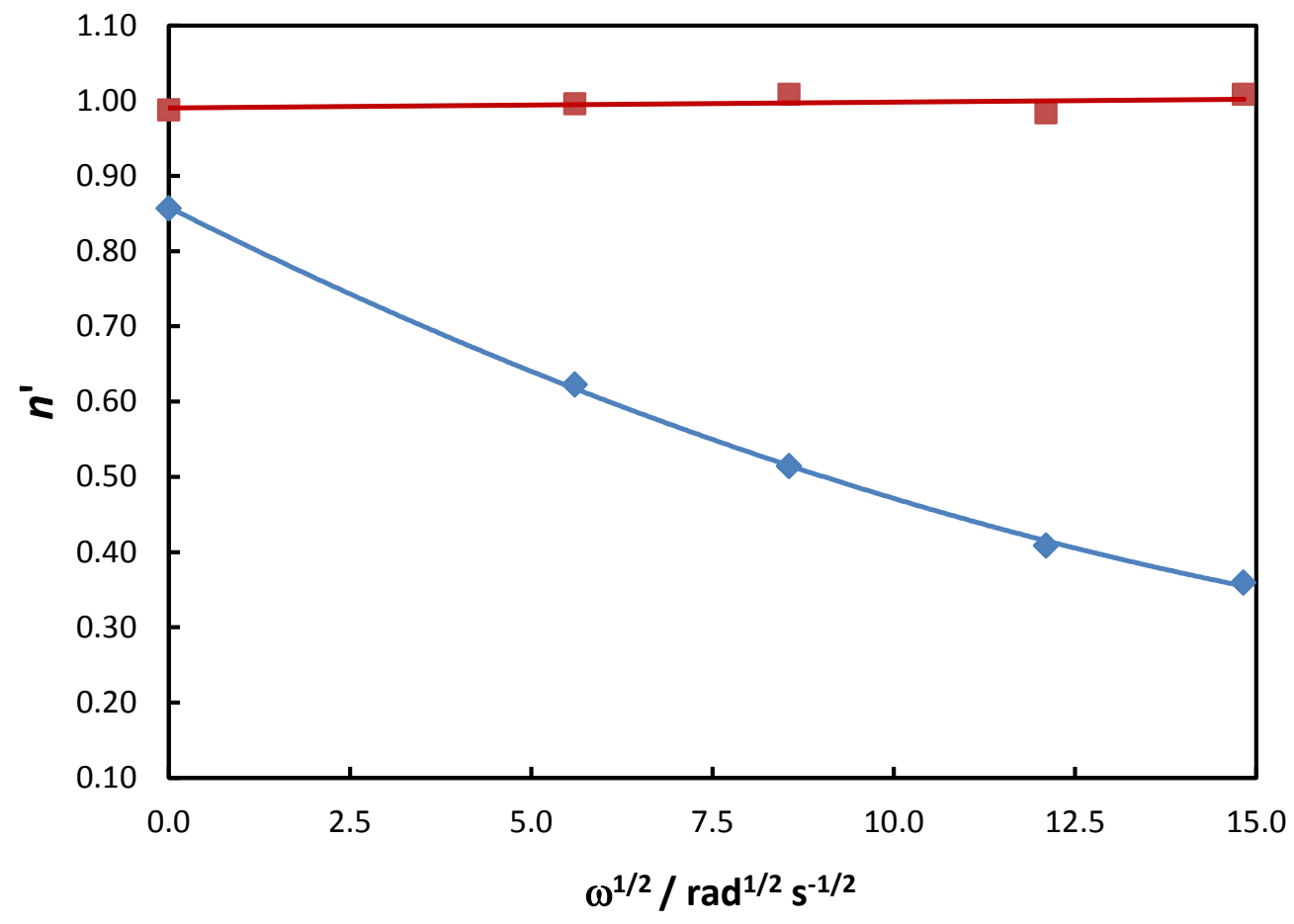

Figure 8: The apparent dissolution valency, $n$, of the copper electrode at $2.85 \mathrm{~mA} \mathrm{~cm}{ }^{-2}$ as a function of the electrode rotation rate, $\omega .(\diamond) 0.20 \mathrm{M} \mathrm{CuCl}_{2}(\bullet) 0.0 \mathrm{M} \mathrm{CuCl}_{2}$ (pure ethaline). 


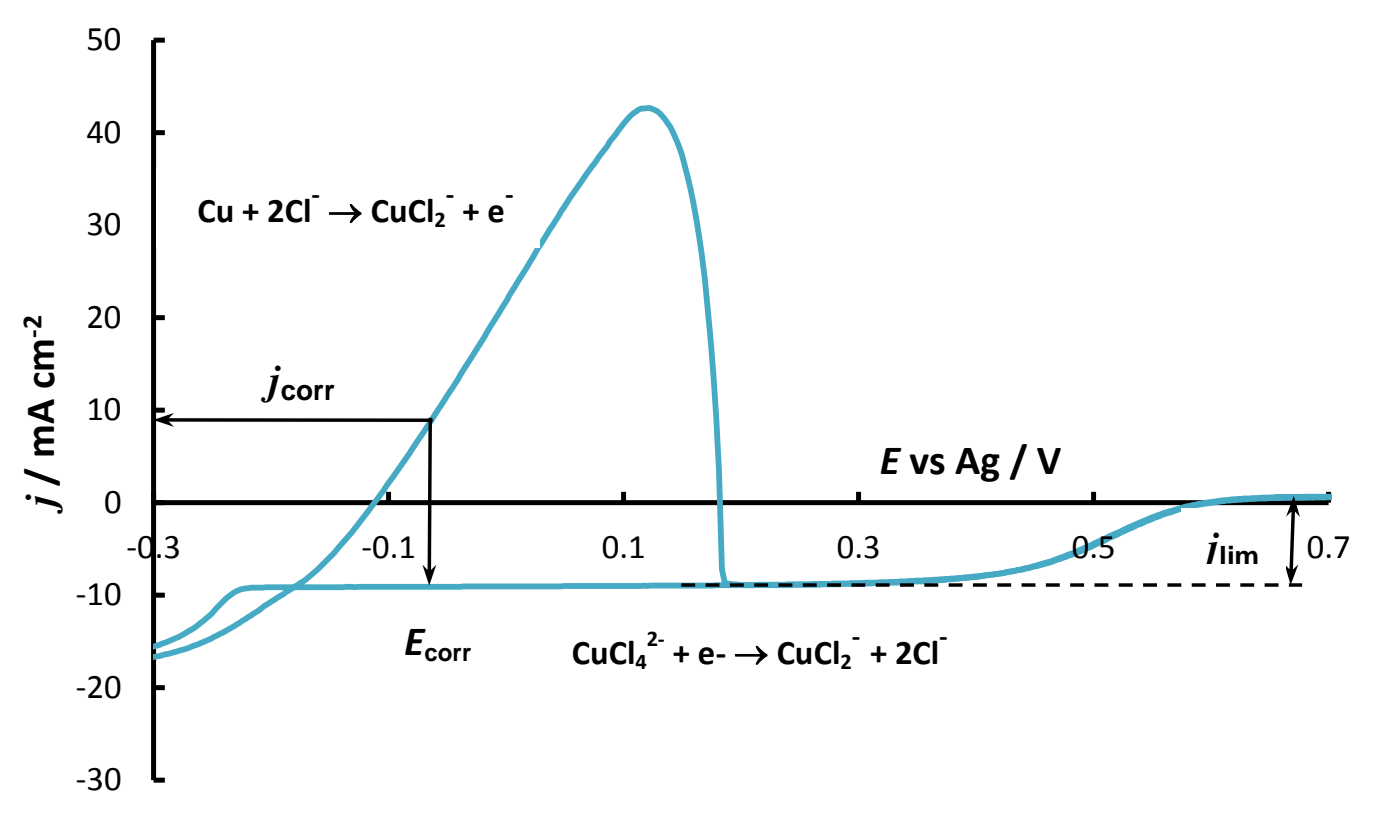

Figure 9: Polariation behaviour of $0.2 \mathrm{M} \mathrm{CuCl}_{2}$ in ethaline $\left(15 \mathrm{wt} \% \mathrm{H}_{2} \mathrm{O}\right)$ at $700 \mathrm{rpm}$ showing coupling of the anodic and cathodic processes under open-circuit conditions, and the resulting $E_{\text {corr }}$ and $j_{\text {corr }}$. 


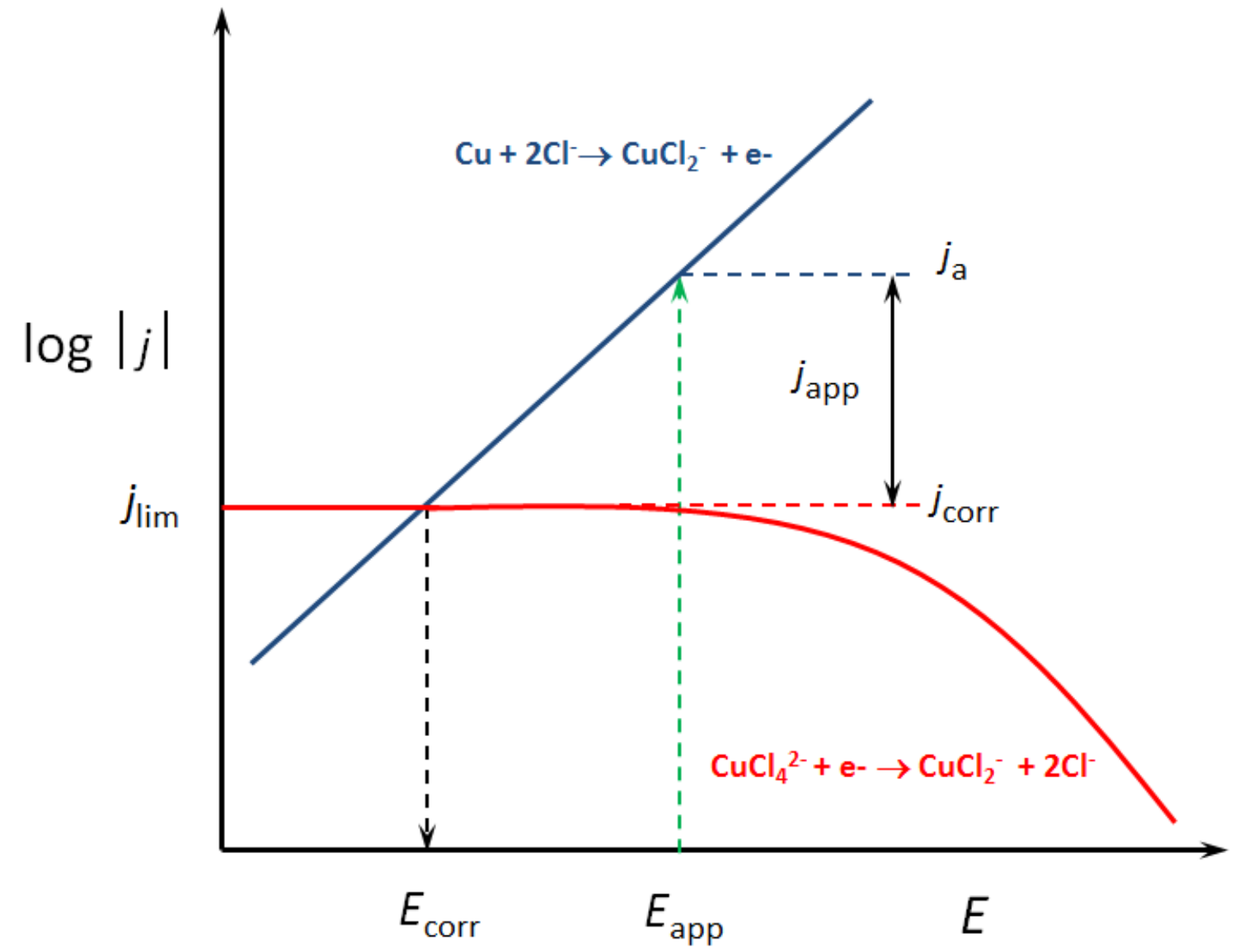

Figure 10: Schematic Evans diagram showing the partial anodic and cathodic reactions for the comproportionation process. Initially the system is at $E_{\text {corr }}$ and the dissolution rate is given by $j_{\text {corr }}$. If an anodic current density of $j_{\text {app }}$ is then applied the dissolution current density increases to $j_{\text {a }}$ and the potential shifts to $E_{\text {app. }}$. 


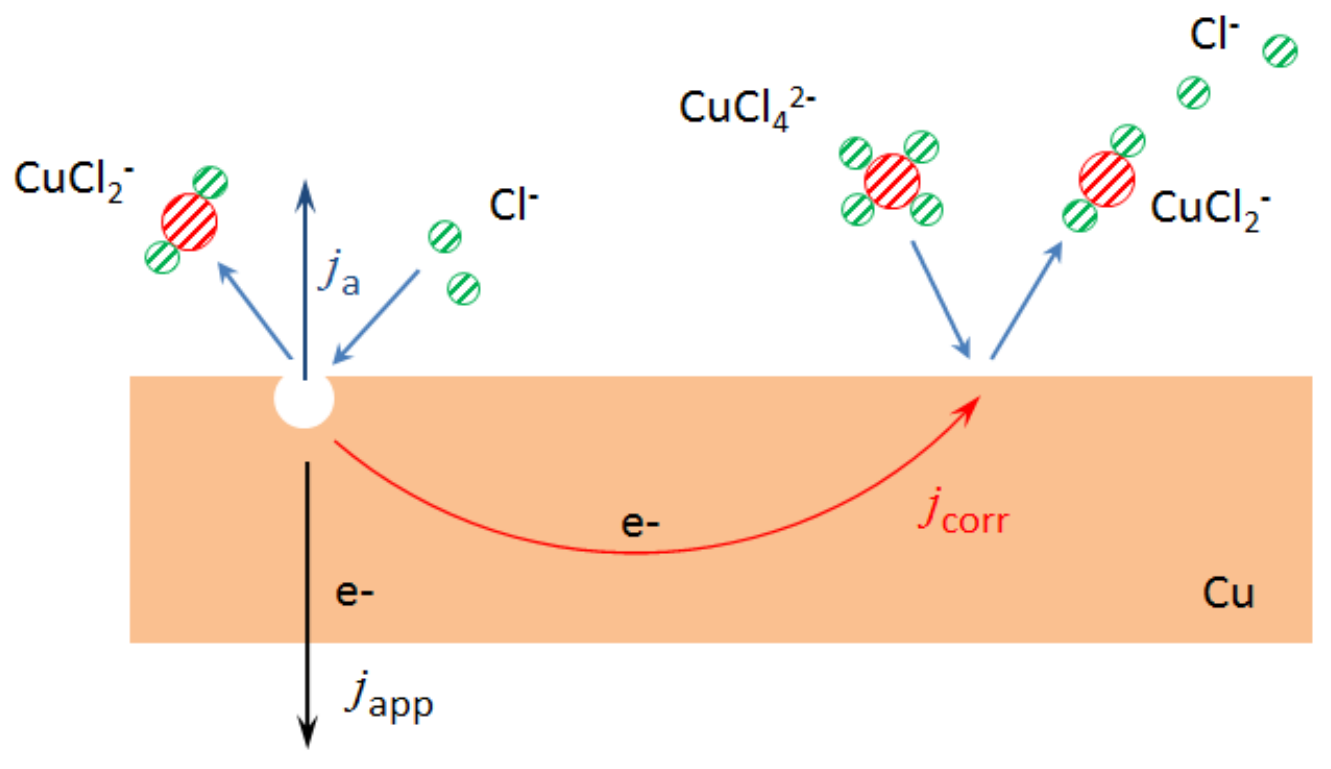

Figure 11: Schematic of the overall dissolution processes showing contributions from normal anodic dissolution and the corrosion reaction. 


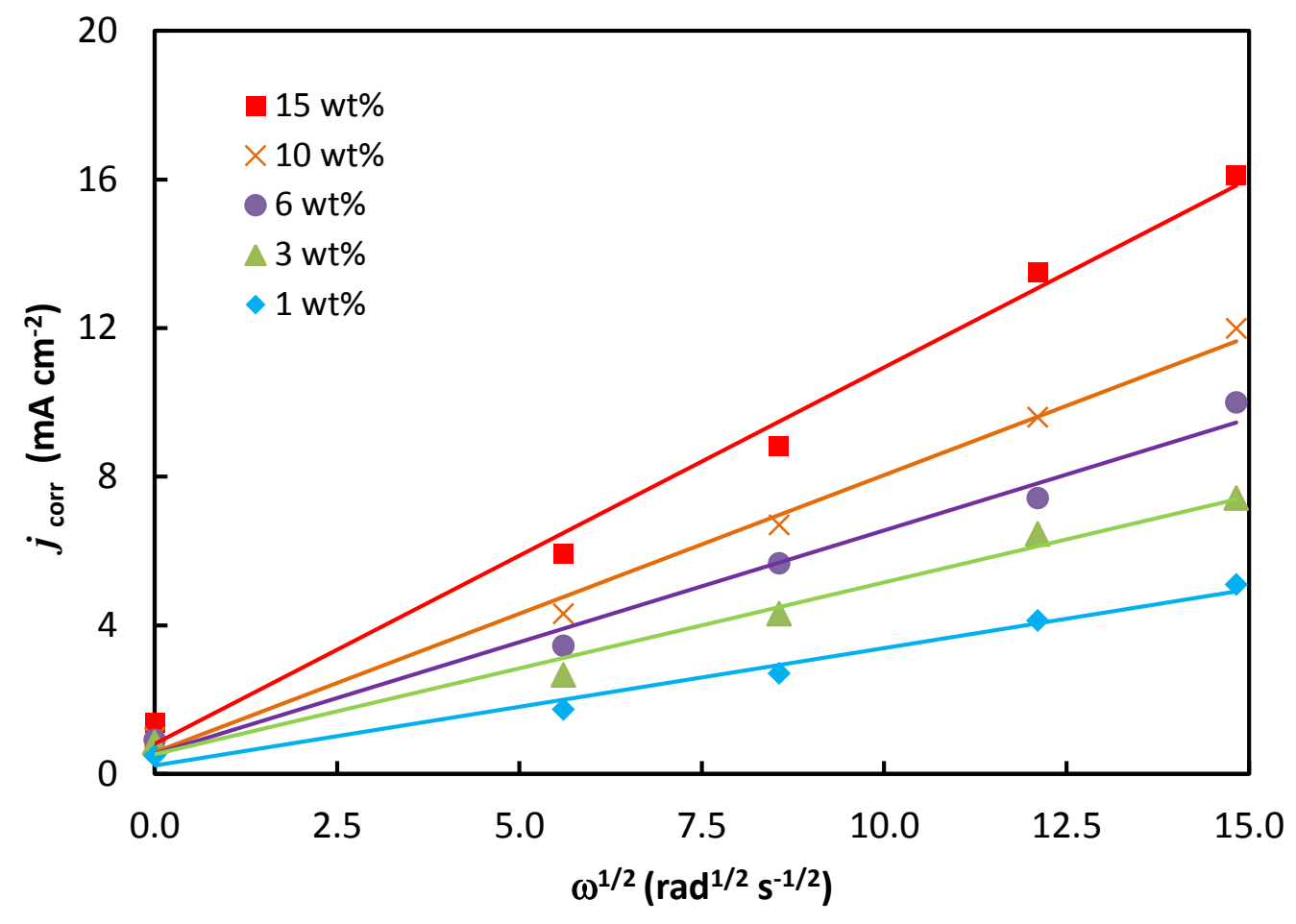

Figure 12: Corrosion current density, $j_{\text {corr }}$, extracted from the dissolution valency data plotted as a function of rotation rate and water content $\left(1-15 \mathrm{wt} \% \mathrm{H}_{2} \mathrm{O}\right)$. 


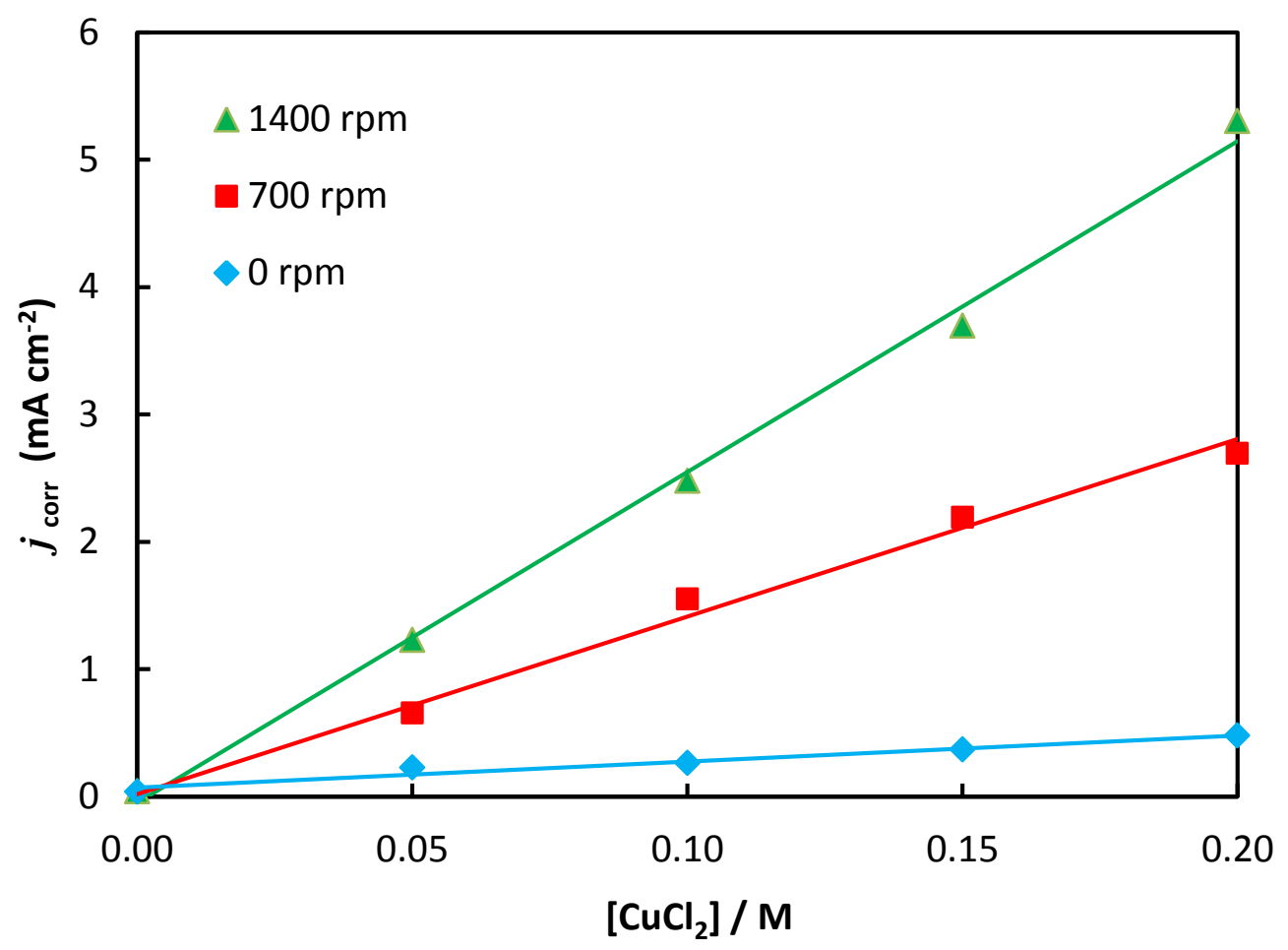

Figure 13: Corrosion current density, $j_{\text {corr }}$, extracted from dissolution valency data as a function of $\mathrm{CuCl}_{2}$ concentration and rotation rate in an ethaline solution containing $1 \mathrm{wt} \% \mathrm{H}_{2} \mathrm{O}$. 